\title{
Management Perspectives On Markstrat: The GE Experience and Beyond
}

\author{
Thomas C. Kinnear \\ The University of Michigan
}

\author{
Sharon K. Klammer \\ General Electric Company
}

\begin{abstract}
Markstrat has attained great success as an educational tool for marketing management. It is also a simulated environment in which academics are now conducting experimental studies on marketing variables and monitoring the impact in the Markstrat context. A most important question that arises in both these types of utilization of Markstrat is the degree to which it reflects the real world of marketing decision making. Do managers from diverse industry experience perceive that Markstrat reflects a real enough marketplace to be useful both as a teaching tool and as a research environment? This article reports the results of a study of this question in the General Electric Company, plus the perceptions of another set of managers drawn from a broad set of other companies. Overall results indicate that managers working in diverse industries believe that Markstrat does reflect a real environment useful for teaching and research.
\end{abstract}

\section{Introduction}

Markstrat is a marketing-strategy simulation game in which five firms compete against each other. This competition is based upon the utilization of the classic marketing variables: product development and management, distribution, promotion, and price. Decision makers in competing firms utilize marketing research studies and develop strategies based upon effective segmentation and positioning. Their performance in the game is based upon such measures as market share, sales, contribution margin, and return on marketing investment (see [3]). In many respects, then, it is a classic strategic marketing situation that a real-world manager would face.

This perceived match between the context of Markstrat and the real world of the marketing manager is the prime reason for the great popularity of Markstrat in MBA and executive-education programs. Recently, because of this perceived match with reality, many academic researchers have begun to use the Markstrat simulation as an environment for studying marketing decision making and other aspects of marketing $[1,2,4]$. 
One problem with both the training and academic research aspects of utilizing Markstrat is that the true match between the real world of the marketing manager and the context of the simulation has never been tested empirically. The key question is: Do managers from diverse industry experiences perceive that Markstrat reflects a real enough environment to be a productive and useful learning experience? The purpose of this article is to present empirical results related to this question. To understand the results of this study, it is also necessary to describe the use of Markstrat within General Electric Company, the source of most of the data utilized in the study. This is the topic that will be discussed first.

\section{Markstrat Within General Electric}

General Electric is a $\$ 39$ billion dollar company operating in diverse sectors of the world economy. Today, it includes, in addition to old-line manufacturing operations such as motors and contractor equipment and well-known consumer goods such as major appliances, high-tech operations such as medical systems and plastics and business-to-business services such as financing and information systems. Working within this diversity, GE's in-house management development center, known as "Crotonville," offers a prescribed sequence of general-management and functional courses to prepare rising executives for top management positions.

At Crotonville these days, the need for quality marketing/sales education is being emphasized as GE struggles for leadership in highly competitive world markets. Marketing courses at Crotonville include basic marketing management, technical sales training, product development, and the Advanced Marketing Management Seminar (AMMS). AMMS is the capstone course in GE's marketing education curriculum. It is in the AMMS course that Markstrat is used. AMMS is targeted at high-potential marketing and other functional managers in GE. AMMS participants typically have significant experience within GE and currently hold jobs that impact the marketplace. They are part of GE's corps d'elite, managers who are tracking toward top-level marketing or general-manager positions. AMMS utilizes cases, lectures, action learning, team problem solving, and the Markstrat simulation to immerse participants in three weeks of marketing decision making. The fundamental purpose of the Markstrat part of AMMS is to provide new strategic insight to the players. The typical class size of 50 is such that two industries of five teams with five participants per team play during each session.

\section{The Study}

In November 1986, a mail questionnaire was sent to participants of six different sessions of AMMS. These respondents had participated in the 1985 and 1986 plays of Markstrat, so their post-Markstrat job experience ranged from 1 to 18 months. The respondents had all used the distributed personal computer version of Markstrat, Markstrat D, with which GE combines customized Lotus 1-2-3 software to enhance players' analytical capability. A profile of the respondents by functional area and the GE business in which they work are presented in Table 1.

The results of Table 1 show the respondents to be a diverse group in terms of both their businesses and their functional areas. Only about $60 \%$ are strictly marketing people. Therefore, the sample is one of great relevance to test the question 
Table 1.

Number of GE AMMS participants surveyed

Number of responses

Respondents' GE Business Affiliation

Technical equipment and services

(Medical systems, transportation, power systems and services)

Industrial flow goods

(Construction equipment, motors, commercial and industrial lighting, GE

supply company, plastics, specialty materials and manufacturing automation)

Consumer Products

(Major appliance, consumer lighting, video and audio products)

Defense

(Aerospace and aircraft engine)

Business-to-business services

(Financial services and information systems)

International

Corporate

Respondents' functional area

Marketing

Sales

Finance

Engineering

Other

Respondens' GE Work Experience

"Grouped by go-to-rmarket approad, not by formal company classificalion. Tliese groupings are neant to be representative; not all company businesses are included.

of interest in this article. However, in order to augment the results of this sample, an additional sample was drawn from Markstrat players from the University of Michigan's Advanced Strategic Marketing Planning seminar that also utilizes Markstrat. The participants in the latter program are drawn from such diverse industries as beer, automobiles, package delivery, pharmaceuticals, plastics, and industrial capital goods. The GE sample was asked both to indicate their attitudes toward Markstrat based on a multiple-choice basis, and to give their open-ended perceptions of the simulation. The Michigan sample was asked only for open-ended responses. The results of both samples are presented in this article.

\section{The Results}

Respondents from GE were first asked a series of questions designed to ascertain their attitudes about Markstrat's relevance to the job environment in which they work (see Table 2). Their responses give insight into Markstrat's general value. The most significant findings, which are summarized in Figure 1 are: 


\section{Tahle 2.}

\section{Markstrat's General Value}

Please indicate which of the following responses most nearly describes Markstrat's influence on the way you manage your business.

1. Since competing in the Markstrat simulation during AMMS, I think about my marketplace:
a. with many fresh and applicable new ideas
b. with a few useful insights
c. the same as before the simulation

2. The Total markstrat experience had the following effect on me: (please circle as many as apply)
a. drove home valuable lessons in marketing strategy
b. taught me new analytical skills and techniques
c. reinforced what $I$ already knew
d. no effect

3. Since competing in Markstrat I can:

a. identify changes in the way I think about my markets due to Markstrat

b. name specific actions I have taken to improve by business's go-to-market strategy that were influenced by the simulation

c. both (a) and (b)

d. Not think of any Markstrat-based changes in the way I approach marketing or business decision making

4. Markstrat's value to me can best be described as (please circle as many as apply):
a. improving my ability to analyze marketing environment
b. increasing my understanding of competitive market dynamics
c. making me feel competent and confident in making key marketing and business decisions
d. none of the above

5. In developing my subordinates, I would:

a. recommend that they compete in Markstrat

b. not recommend Markstrat as a good use of their time

c. not applicable (e.g., respondent has no subordinates)

\section{Markstrat's Specific Characteristics}

Please indicate which response most nearly describes Markstrat as a teaching vehicle.

6. Markstrat is a realistic simulation of competitive market forces.
a. agree
b. agree somewhat
c. disagree somewhat
d. strongly disagree

7. Markstrat emphasizes the imiportance of accurate market segmentation and focused product positioning.
a. agree
b. agree somewhat
c. disagree somewhat
d. strongly disagree

8. Markstrat reinforces the importance of achieving dominance in well-defined market segments.
a. agree
b. agree somewhat
c. disagree somewhat
d. strongly disagree

9. Markstrat emphasizes the use of market research to anticipate customer needs.
a. agree
b. agree somewhat
c. disagree somewhat
d. strongly disagree

10. Markstrat stresses the strategic value of leapfrogging competition with new product introductions.
a. agree
b. agree somewhat
c. disagree somewhat
d. strongly disagree

11. Markstrat illustrates the value and limitations of advertising.
a. agree
b. agree somewhat
c. disagree somewhat
d. strongly disagree

12. Markstrat stresses the importance of being the low-cost producer (the experience curve effect).
a. agree
b. agree somewhat
c. disagree somewhat
d. strongly disagree 
Table 2. (continued)

13. Markstrat emphasizes the linkages between focused product positioning, segment dominance, accurate pricing, and product profitability.
a. agree
b. agree somewhat
c. disagree somewhat
d. strongly disagree

14. Markstrat reinforces the necessity of exiting unprofitable market segments and/or eliminating low-share product.
a. agree
b. agree somewhat
c. disagree somewhat
d. strongly disagree

15. Markstrat stresses the importance of targeting resources such as new product development, advertising, promotion, sales, and distribution expenditures on those products/segments where you are best positioned to dominate.
a. agree
b. agree somewhat
c. disagree somewhat
d. strongly disagree

Markstrat's Impact on Marketing Decision Making

16. Describe specific marketing actions you initiated on your job base on your Markstrat experience.

17. What were the most important lessons you learned from Markstrat?

18. Identify analytical tools and techniques learned in Markstrat that you use on your job.

19. What would say is Markstrat's greatest strength?

1. Ninety-four percent of respondents indicate that Markstrat has given them at least a few useful insights about their marketplace, while $26 \%$ indicate that they have gained many fresh and applicable new ideas. This outcome is consistent with the fact that AMMS participants are predominately seasoned GE managers with an average of 11 to 15 years of marketing and/or general business experience. One would not expect a high percentage of such a group to perceive that the simulation introduced them to totally new marketing ideas.

2. Fifty-nine percent think that Markstrat drove home valuable lessons in marketing strategy, while $60 \%$ indicate that Markstrat has taught them new analytical skills and techniques.

3. Seventy percent can identify changes in the way they think about their markets since competing in Markstrat, and an impressive $39 \%$ can actually name specific actions they have taken to improve their businesses' go-to-market strategies based on what they learned from the simulation.

4. Seventy-seven percent see Markstrat as increasing their understanding of competitive market dynamics, while $43 \%$ thought that Markstrat had improved their ability to analyze their marketing environment. $25 \%$ think that the game has made them feel competent and confident in making key marketing and business decisions. These results are, again, consistent with the marketing background and experience level of AMMS participants.

5. Of those to whom the question applied, $91 \%$ see Markstrat as an experience that they would recommend for their subordinates as part of their development.

In addition, a series of questions about Markstrat's specific characteristics was asked in the GE survey. A summary of participant responses as shown in Figure 2 indicates: 


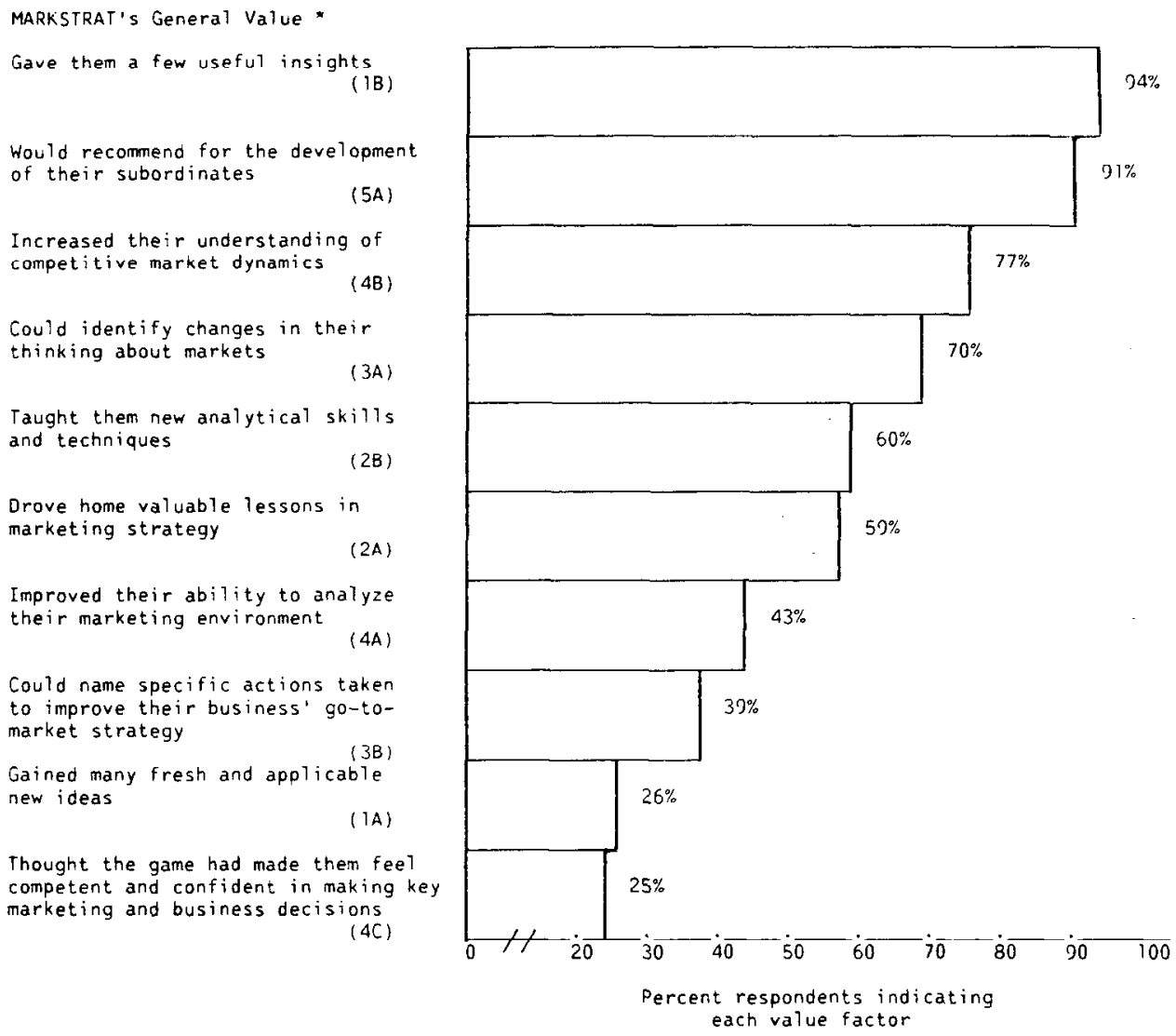

* Survey question numbers are indicated in ( )

Figure 1. Responses to survey questions 1-5.

6. Ninety-three percent agree that Markstrat is a realistic simulation of competitive market forces.

7. Ninety-nine percent of the participants think that Markstrat emphasizes the importance of accurate market segmentation and focused product positioning. This is an important result since the simulation was designed to teach these key marketing concepts.

8. Ninety-seven percent believe that the game reinforces the importance of achieving dominance in well-defined market segments.

9. Ninety-three percent indicate that the simulation emphasizes the use of market research to anticipate consumer needs.

10. Ninety-four percent see Markstrat as stressing the strategic value of leapfrogging competition with new product introductions.

11. Eighty-eight percent think that the game illustrates the value and limitations of advertising.

12. Ninety-one percent indicate that the simulation stresses the importance of being the low-cost producer. 


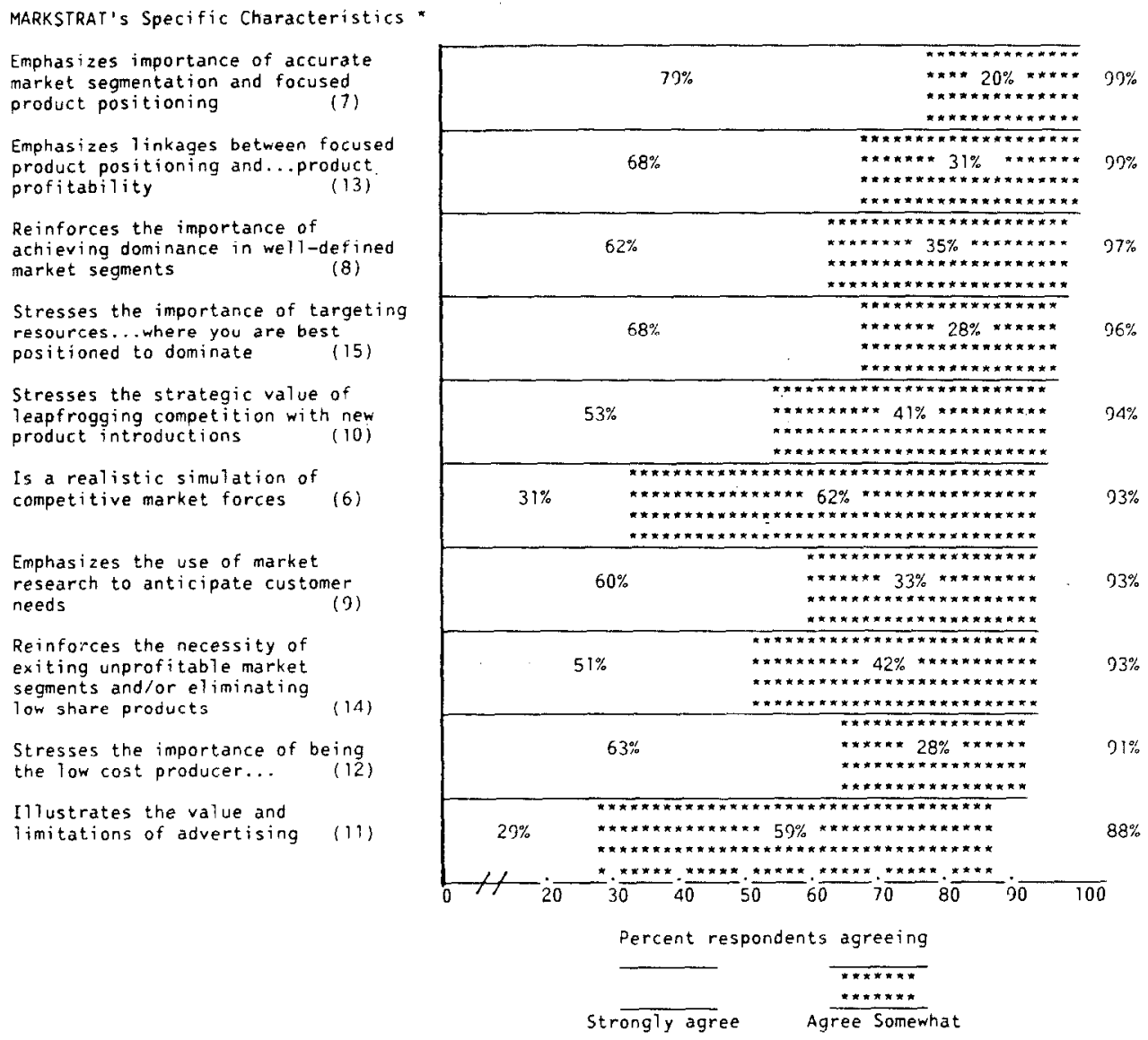

* Survey questions numbers are indicated in ( )

Figure 2. Response to survey questions 6-15.

13. Ninety-nine percent of respondents bleieve that Markstrat emphasizes the linkages between focused product positioning, segment dominance, accurate pricing, and product profitability.

14. Ninety-three percent think that the game reinforces the necessity of exiting unprofitable market segments and/or eliminating low-share products.

15. Ninety-six percent believe that Markstrat stresses the importance of targeting resources such as new product development, advertising, promotion, sales, and distribution expenditures on those product/segments where the firm is best positioned to dominate.

In summary, most participants surveyed believe that Markstrat emphasizes critical elements of marketing strategy. The fact that $50 \%$ or more of respondents strongly agree with 8 of the 10 statements in this section reinforces the simulation's value as a teaching vehicle. It is particularly impressive that $93 \%$ of those responding believe that Markstrat is a realistic simulation of competitive market forces with 
Table 3. Describe Specific Marketing Actions You Initiated on Your Job Based on Your Markstrat Experience

"I reviewed our marketing plans based on segment strengths and weaknesses. I then revised specific segment plans based on size of market estimate/strengths analysis." (marketing manager, consumer electronics)

"I redefined our product plan '87 and revisited recent market research to pick up trends and improve our anticipation. I am now preparing the introduction of a product which does not currently exist in the marketplace." (product manager, CAMCO, Canadian GE)

"I created a data base for competitive analysis . . and redefincd our busincss arcas. ..." (busincss development manager, aerospace)

"I did some product pruning to ensure targeted products and made some price modifications changing from cost based to value based pricing." (manager, marketing analysis and support, commercial and industrial lighting)

"I initiated several research projects to evaluate competitive pricing and positioning. I then established a 'perceived value' comparison roughly based on a two-dimensional mapping of product quality versus product features. This led to cost improvements or major service lines and projects." (manager, corporate systems marketing, GE Information Services, Inc.)

"I increased our advertising segmentation and our use of print advertising to target more finely." (product manager, consumer lighting)

"I compared one of our new products to competitors' products to properly position and price the new product ... the Markstrat experience was a major asset in developing this positioning." (specialist, magnetic resonance marketing, medical systems)

$31 \%$ strongly agreeing with this statement. When the diversity of businesses represented in the sample is considered, this outcome argues that Markstrat approaches the ideal of a truly generic simulation, relevant to virtually all go-to-market endeavors.

In addition to the scale-based results presented above, respondents were asked a series of open-ended questions to ascertain Markstrat's impact on marketing decision making. The first of these questions dealt with the specific marketing actions that participants initiated on their jobs based on their Markstrat experience. Table 3 presents selected quotes of respondents. Overall, these responses indicate that the game has had a significant impact on these managers.

The second question asked respondents to name the most important lessons learned from Markstrat. Table 4 represents selected responses to this question. These quotes indicate that participants are learning the lessons that Markstrat is designed to teach.

The third area of interest was concerned with the specific analytical tools and techniques that were learned in Markstrat that are being used on the job. Although Markstrat's main purpose is to teach strategic marketing thinking and not the development of specific analytical skills, many participants were able to identify tools and techniques that they are really using on the job based upon the Markstrat experience. Table 5 presents selected responses.

Also, respondents were asked to identify Markstrat's greatest strength. Selected results are presented in Table 6 . These comments serve as a useful summary of the great impact that Markstrat has as a teaching device and as a realistic laboratory setting for research.

As a final check on the impact of Markstrat on real managers, Table 7 presents 
Table 4. What Were the Most Important Lessons You Learned from Markstrat?

"If you don't get to market first with the best product, you get hammered." (manager, new business development, plastics)

"Segmentation commitment to a strategy based on thorough analysis." (manager, operational planning, GE Financial Serices, Inc.)

"- Product positioning

— Value of advertising

- Identifying consumer needs

- Importance of achieving low cost status in the marketplace." (manager, financial analysis, major appliance)

"The need to focus resources selectively in product/markets in which you have competitive edge. Importance of matching product with consumer perceptions of what is required." (manager, financial planning, power systems)

"That market research information, when properly analyzed and correctly used, can be a powerful tool in developing new products and planning new business penetrations." (manager, marketing, aerospace)

"Advertising and price strategies cannot overcome the deficiencies of a poorly designed product." (manager, market research, commercial and industrial lighting)

"- Pricing is a product attribute, not a consequence

- Clearly analyze relevant costs vs. direct product costs

- Find ways to maintain long-term advantage." (services project manager, power systems)

"Leapfrog and low cost or you won't win." (manager, manufacturing and equipment technology, contractor equipment)

Table 5. Identify Analytical Tools and Techniques Learned in Markstrat that You Use on Your Job

"Monitoring competitive marketing actions." (manager, pricing analysis, major appliance)

"- Market research and competitor analysis techniques

- Distribution channel analysis

- Perceptual mapping." (area manager, construction equjpment)

"Competitive analysis based on perceptual mapping." (manager, new business development and automotive sales, motors)

"Trend identification and prediction." (manager, materials, manufacturing and quality technology marketing, aircraft engine)

"Enhanced spread sheet analysis, more 'what if' simulations and use of improved math models for forecasting." (manager, business operations, aircraft engine)

"Use of Lotus 1-2-3 as a management tool not just as a single spreadsheet." (regional manager, GE Information Services, Inc.)

"I am now using Lotus 1-2-3 to kcep track of all proposal/customer activity. I can sort the data to show types of applications, units, etc. This data shows me market trends." (manager, industrial marketing support, power systems)

"I am using the PC for upfront analysis of sales programs, competitive price tracking, product line price tracking and price/share/volume trade-offs." (regional manager, major appliance) 
Table 6. What Would You Say Is Markstrat's Greatest Strength?

"Markstrat brings you close to a real world situation ... a very competitive marketing environment." (manager, business development, GE Mexico)

"Teaching me that the dynamics of competitive markets are driven both by consumer needs and product development." (manager, field market development, plastics)

"Changing my sales mind set to make me more aware of the positive value of advertising and competitive changes in the marketplace." (regional sales manager, GE Information Services, Inc.)

"Its realism in simulating the market environment with a large number of variables." (manager, advanced marketing, aerospace)

"Its ability to gain the player's undivided attention and interest. It didn't feel like a game." (manager, industrial product planning, motors)

"In a short period of time most, if not all, strategic market forces are utilized in a competitive, fun exercise." (financial analyst factory automation)

"It is extremely lifelike. Even for the nonconsumer product portion of our Company the lessons are the same... we just have fewer but more powerful buyers." (manager, advanced engine system marketing, aircraft engine)

"It's like time lapse photography. It speeds up the product life cycle and simplifies the market so that you can clearly see the effects of your decisions." (service manager, power systems)

Table 7. Quotes from Non-GE Managers from Michigan Programs

"Good practical way to review/experience interaction of different parameters affecting business. Better understanding of interaction of marketing elements." (beer company sales and distribution vice-president)

"Confirmed a thinking process and reinforced awareness of the dynamic market process particularly the competitive activity. It also placed the marketing process in context and the relative importance of the various marketing mix elements. The experience emulated the real world and sharpened the senses." (international sales and promotion manager for major automobile company)

"I have begun to champion an on-going and informationally consistent market research effort. I now recognize that to be 'market driven' it is imperative to evaluate buyers and their motives. I enjoyed the 'adventure, chills and thrills' that ensued." (senior marketing manager for a major overnight delivery service)

"It took away the mystique of complex problem solving. It gave very good insight on how to look at a problem analytically and to break it down into segments that have meaning and direction." (market manager for a major industrial supplier of capital products)

"It helped paint a single picture of marketing strategy using all the elements at once. I've become more precise in my requests to market research. I also have begun to think more in terms of where the market will be tomorrow rather than where it is today." (senior product manager for a major ethical drug company)

"It came at a time in my career when the strategic market planning concept was being implemented by my company. It helped to clear my understanding of the concept and sharpen my skills." (director of distribution for a major plastics company)

"We have "positions' for all new products based on the same basis learned." (advertising and merchandising manager for the truck division of a major automobile company) 
selected results from the group of non-GE managers who played Markstrat at the University of Michigan program. The consistenttly powerful impact of the experience is again noted.

\section{Discussion}

Those who have used Markstrat as an educational device have consistently praised its impact on students and managers for years. The problem with this praise has been that it has been based upon general impressions and isolated comments of participants. This study is the first to explicitly measure the educational impact of Markstrat on a managerial audience. Markstrat's power to teach important marketing concepts and reflect the marketplace and competitive realities of diverse businesses is well documented in the results presented here. What is even more impressive is that real managers take real action based upon their Markstrat experience. It is a truly powerful teaching tool.

There is also a profound conclusion for academic researchers in these results. One of the great problems facing academic researchers who study marketing decision making is to find a manageable environment that is also real enough to provide external validity to the results of these studies. The results presented indicate strongly that Markstrat is such an environment.

\section{References}

1. Bovich, Edward, The Impact of Marketing Decision Support Systems on Marketing Decision Making. Unpublished Ph.D. Dissertation, The University of Michigan, Ann Arbor, 1987.

2. Cook, Victor J. Jr., and Page, John R. Assessing Marketing Risk, Journal of Business Research 15 (1987).

3. Larreche, Jean-Claude, and Gatignon, Hubert, MARKSTRAT: A Marketing Strategy Game. The Scientific Press, Palo Alto, Calif., 1977.

4. Utsey, Marjorie, F., A study of the Achievement of Profit Potential in a Simulated Environment. Unpublished Ph.D. disseratation, Tulane University, New Orleans, 1985. 